\title{
Embodied Technical Change And The Fluctuations Of Wages And Unemployment*
}

\author{
Michael Reiter \\ Universitat Pompeu Fabra, Barcelona
}

October 2006

\begin{abstract}
The paper shows that a matching model where technological change is partially embodied in the job match is successful in explaining the variability of unemployment and vacancies. If we incorporate long-term wage contracts into the model, it also explains a number of stylized facts on the dynamics of real wages, which have been found in the empirical labor literature.
\end{abstract}

JEL classification: E24, E32, J64

Keywords: Unemployment, wage dynamics, embodied technical change

Address of the author:

Michael Reiter

Universitat Pompeu Fabra

Department of Economics and Business

Ramon Trias Fargas, 25-27

08005 Barcelona

Spain

e-mail: michael.reiter@upf.edu

*I am grateful to James Costain, Christian Haefke and Thijs van Rens for many helpful discussions on the topics of this paper. Financial support from Spanish ministry grants SEJ2004-03619 and SEC200201601 is gratefully acknowledged. 


\section{Introduction}

Shimer (2005) and Costain and Reiter (2003) have documented that the standard labor market matching model has problems in explaining the fluctuations of unemployment and vacancies. The purpose of this paper is to investigate whether these problems can be solved by adopting a somewhat different specification of technical progress. Standard RBC models, including the basic versions of the Mortensen/Pissarides model, assume that changes in aggregate productivity affect equally all firms and production processes. An alternative view with long tradition is that technical progress is embodied in new investment goods, and that only the new capital vintages enjoy the increase in productivity. In this paper I investigate the hypothesis that technical change is embodied, at least partially, in the match between a firm and a worker. What motivates this change in the specification of technology is the view that a boom is a time that offers many opportunities to firms. Many new ideas are around, new products and new markets are created, and firms strive to be the first in implementing ideas and conquer a share of the new markets. Even after entering a recession, where new ideas are scarce, the jobs that were created during good times keep a part of their productivity advantage. We can summarize this idea in the following

Hypothesis 1. In the cross section of jobs that exist at any given point in time, the jobs that have been created in a boom have on average higher total factor productivity (keeping quality of labor and the capital stock fixed) than the jobs that have been created in a recession.

This view of technology has some similarity to investment-specific technology shocks, which Fisher (2006) finds to have an important role in explaining business cycle fluctuations. An investment specific shock is embodied in the capital that is created while technology is favourable. In our case, the shock is embodied in the quality of the employment relationships. To have the most parsimonious representation of this idea, I will assume in this paper that there is only one aggregate technology shock, and that labor productivity takes the following form:

$$
Y\left(z, z_{m}\right)=\left(1-\alpha_{z}\right) z+\alpha_{z} z_{m}, \quad 0 \leq \alpha_{z} \leq 1
$$

Here, $z$ is the current level of aggregate productivity, and $z_{m}$ is the level of aggregate productivity prevailing at the time when the match was formed. The technological specification in standard RBC models is a special case of (1), where $\alpha_{z}=0$. For $\alpha_{z}>0$, technological change is partially "embodied" in the match. Note that I abstract from capital in production, following most of the labor market matching literature,

The consequences of the specification (1) in a standard matching model were briefly investigated in Costain and Reiter (2003, Section 4.4), and it was found that it can lead to a substantial increase in the variability of unemployment. ${ }^{1}$ The intuition is the following. If

\footnotetext{
${ }^{1}$ Hornstein, Krusell, and Violante $(2006)$ embed labor market frictions into a model where technical progress is embodied in capital investment. They only analyze steady states, and it is not clear whether the mechanism investigated in the present paper would be at work there as well.
} 
a new match is formed in a boom, the high productivity is partially embodied in the match, and will persist even if a recession comes. The possibility that a recession may arrive while the match continues, reduces the outside option of the worker, while the outside option of the firm is always zero. This tends to increase the fraction of the product of labor going to the firm, and hence the value of a match to the firm fluctuates more strongly over the cycle. This creates bigger fluctuations in vacancies, hiring and unemployment. On the negative side, it was found that this model creates a grossly counterfactual variability of wages. In this paper, I choose a recently developed version of the matching model with long-term wage contracts (Rudanko 2005), to see whether this combination can explain both the dynamics of unemployment, vacancies etc., and the dynamics of wages. Since the cyclicality of wages is hard to measure, I will use both macro- and microeconometric evidence to evaluate the success of the model.

It is probably difficult to test Hypothesis 1 or the specification (1) directly, because of composition bias in the workforce over the cycle, effects of changes in the capital stock and other issues. I interpret the evidence in Bowlus (1995) as supportive of Hypothesis 1. She finds that jobs that are created in recessions pay lower wages and dissolve more quickly than jobs created in booms. Moreover, "... the impact on tenure is greater for highereducated workers and those employed in professional industries. This evidence suggests the cyclical phenomenon is one of general mismatching and not of workers taking stopgap jobs during recessions to get by." (Bowlus 1995, p.347). If the jobs created in recessions had the same productivity as jobs created in booms, and the wage differential was only a consequence of wage contracting, we would expect workers to renegotiate their wages when the boom arrives, but not to change the employer.

The aim of this paper is to test Hypothesis 1 in an indirect way. We will see that putting the specification (1) into a labor market matching model has strong implications for labor market aggregates and for real wages, which can be tested against macro and micro data. The results are largely favourable. The model goes a long way in explaining the high variability of unemployment and of labor market tightness over the cycle, in contrast to matching models with a standard RBC technology. With long-term wage contracting as in Rudanko (2005), the model's implications for wages are mostly consistent with the data.

The plan of the paper is as follows. The model is presented in Section 2. Section 3 looks at the case of continuous Nash bargaining, for which results can be derived analytically. Section 4 briefly describes the data that the model is supposed to match, and discusses parameter choices. The main results are in Section 5. Section 6 concludes. Details of the computational procedures are given in an appendix that can be downloaded from "http://www.econ.upf.es/ reiter/research.html".

\section{Model}

The model I use is very similar to Rudanko (2005). The main difference is the more general technology specification (1), while Rudanko works with the traditional RBC formulation 
$\left(\alpha_{z}=0\right)$. This has some consequences for the contracting problem of workers and firms.

The economy is populated by a unit mass of workers. Workers order consumption streams according to the utility function $\mathrm{E}_{t} \sum_{i=0}^{\infty} \beta^{i} U\left(c_{t+i}\right)$. The concavity of $U$ implies risk aversion, but we assume that workers do not have access to the capital market; they can neither borrow nor save. ${ }^{2}$ Therefore, their consumption equals their wage $w_{t}$ while employed, and the constant $b$ while unemployed. We will refer to $b$ as "unemployment benefits", but following most of the matching literature, we effectively treat it like home production. This means in particular that we do not take into account that $b$ has to be financed by a government through taxes etc.

A firm is a filled job. It employs one worker and produces output according to the production function (1). In each period, the firm becomes permanently unproductive with probability $\delta$. In this case, the match dissolves and the worker becomes unemployed. Whenever a match separates, either endogenously or exogenously, we assume that the vacancy (the firm) disappears. This is not an innocuous assumption in our setup, and we discuss in Section 2.5 what happens if we modify it. We assume that firms are owned by risk neutral entrepreneurs, but we effectively ignore the entrepreneurs in the analysis of the model (they consume profits in every period, and we do not worry about their consumption being positive or not). The asymmetry between risk-neutral entrepreneurs and risk averse workers provides an incentive to long-term wage contracting where firms insure workers against wage fluctuations.

\subsection{Matching Technology}

The measure of unemployed workers is denoted by $U$, and the measure of open vacancies by $V$. New jobs are created according to the matching function

$$
M=A_{m} U^{\alpha} V^{1-\alpha}
$$

We define labor market tightness as $\theta=\frac{V}{U}$. Then we can write the probability of a firm to fill the vacancy as $p^{F}=\frac{M}{V}=A_{m} \theta^{-\alpha}$ and the probability of a worker to find a job as $p^{W}=\frac{M}{U}=\theta p^{F}=A_{m} \theta^{1-\alpha}$.

\subsection{Short-Term Wage Contracts}

We first consider the case that is closest to the standard Mortensen/Pissarides model. Denote by $F\left(z, z_{m}\right)$ the value of a filled job to the firm, and by $V\left(z, z_{m}\right)$ the value of a job to the worker. They are both a function of the current state of productivity $z$ and the productivity of the time when the match was formed, $z_{m}$. The value of being unemployed is denoted by $V^{u}(z)$ and depends only on current technology.

\footnotetext{
${ }^{2}$ This assumption, in particular the part that households cannot save, is overly strong and is only made to keep the contracting problem of workers and firms tractable. Beaudry and Pages (2001) give a calibration where it is an equilibrium outcome that workers do not save.
} 
In the states $\left(z, z_{m}\right)$ where there is a positive match surplus and the match is continued, we have

$$
\begin{aligned}
& V\left(z, z_{m}\right)=u\left(w\left(z, z_{m}\right)\right)+\beta \mathrm{E}_{z}\left[(1-\delta) V\left(z^{\prime}, z_{m}\right)+\delta V^{u}\left(z^{\prime}\right)\right] \\
& F\left(z, z_{m}\right)=Y\left(z, z_{m}\right)-w\left(z, z_{m}\right)+\beta(1-\delta) \mathrm{E}_{z} F\left(z^{\prime}, z_{m}\right)
\end{aligned}
$$

Under the productivity specification (1), however, the match surplus is not always positive, so that there is the possibility of endogenous separation. If $z>z_{m}$, the match has lower productivity than the new matches that are currently created, and it may be better for the firm and the worker to separate. In fact, the evidence reported by Bowlus (1995) indicates that this does in fact happen. Nevertheless, we will see later that if this happens too often, the model generates some dynamics that are clearly at odds with the aggregate data. We therefore have to put a mechanism into the model to dampen or eliminate endogenous separations, and the easiest way to do this is a sunk cost $\kappa_{M}$ that has to be paid directly after the match is formed. Since the worker has no access to the capital market, this cost can only be paid by the firm. The Nash-bargaining is then about the match surplus minus the sunk cost. That means we assume away the hold-up problem that comes with the sunk cost: the worker does not appropriate the initial investment made by the firm. With short-term contracts, the wage is continuously re-bargained, and the following Nash bargaining conditions has to hold in each period during the match:

$$
\alpha\left(F\left(z, z_{m}\right)-\kappa_{M}\right) u^{\prime}\left(w\left(z, z_{m}\right)\right)=(1-\alpha)\left(V\left(z, z_{m}\right)-V^{u}(z)\right)
$$

The firm value $F\left(z, z_{m}\right)$ is always understood as value after paying the sunk cost. We use in (5) that the outside option of the firm is always zero. This is because vacancies disappear after a match is separated, and new vacancies can be freely created such that a zero profit condition holds, see Equ. (12).

\subsection{Long-Term Wage Contracts}

We will see in Section 5 that the model with continuous re-bargaining creates excessive volatility of wages compared to the data. This problem is the more severe the bigger is the embodied part of technological change. We therefore investigate whether a model with long-term wage contracts can bring the model in line with the data.

We now assume that worker and firm sign a wage contract at the beginning of the employment relationship. A contract that is signed in period $t$ specifies a sequence of wage payments $w_{t+i}\left(z^{t+i}\right), i=0,1, \ldots$ Each wage is conditional on the history of shocks $z^{t, t+i}=\left(z_{t}, z_{t+1}, \ldots, z_{t+i}\right)$. No wage payments can be made after the separation of the match.

Worker and firm choose a contract that is privately efficient (that means, it is impossible to make both firm and worker better off). The set of efficient contracts can be characterized by the firm's expected profit function $F\left(V, z, z_{m} ; V^{u}().\right)$. It is a function of the current state of technology $z$, the technology at the time the match was formed, $z_{m}$, and the expected value that the firm has promised to the worker, $V$. We treat $V$ here as a choice parameter 
of the firm; the higher $V$, the lower will be the profit that the firm can earn from the employment relationship. The firm's profit function also depends on the outside option of the worker in the different states of nature, $V^{u}($.$) . Note that, once firm and worker have$ separated, the only relevant state variable is current technology $z$. The outside option is therefore a function of $z$ only, $V^{u}(z)$. For notational simplicity, we suppress this argument and simply write $F\left(v, z, z_{m}\right)$.

The firm's profit function under limited commitment satisfies the functional equation

$$
F\left(v, z, z_{m}\right)=\max _{w, V\left(z^{\prime}\right)}\left\{Y\left(z, z_{m}\right)-w+\beta \mathrm{E}_{z}(1-\delta) F\left(V\left(z^{\prime}, z_{m}\right), z^{\prime}, z_{m}\right)\right\}
$$

subject to

$$
\begin{aligned}
v & =u(w)+\beta \mathrm{E}_{z}\left[(1-\delta) V\left(z^{\prime}, z_{m}\right)+\delta V^{u}\left(z^{\prime}\right)\right] \\
V\left(z^{\prime}, z_{m}\right) & \geq V^{u}\left(z^{\prime}\right), \quad \forall z^{\prime} \\
F\left(V\left(z^{\prime}, z_{m}\right), z^{\prime}, z_{m}\right) & \geq 0, \quad \forall z^{\prime}
\end{aligned}
$$

The inequality (6c) is the condition that the worker wants to continue in the match. Inequality (6d) is the analogue for the firm. In the case of one-sided commitment, only the participation constraint of the worker, (6c), not the participation constraint of the firm, (6d), is enforced. In the case of full (two-sided) commitment, neither (6c) nor (6d) are imposed. Rudanko (2005, Section 2) derives some properties of optimal contracts. In particular, the wage stays constants over the match as long as no participation constraint binds. If, for example, the constraint (6c) starts binding, the firm has to increase the wage to keep the worker within the firm. In the full-commitment case, the wage is constant over the life of the match.

Just as in the case of short-term contracts, the issue of endogenous separation arises. It may be that there is no way to satisfy (6c) and (6d). With one-sided commitment, the contract that guarantees the worker her outside option may imply a negative value for the firm. In those cases, a Pareto-efficient solution implies to separate the match. This requires some modification of the above setup. However, I do not go into the details here. because the numerical experiments below for the case of long-term wage contracts will use a value of the sunk cost $\kappa_{M}$ such that all matches are continued.

It remains to determine which of the contracts on the efficiency frontier is chosen. We assume that, when firms and workers are matched in the aggregate state $z$, they chose the optimal contract with the entry value $V^{e}(z)$ that maximizes the Nash product ${ }^{3}$

$$
V^{e}(z)=\underset{v}{\operatorname{argmax}}\left(v-V^{u}(z)\right)^{\alpha}\left(F(v, z, z)-\kappa_{M}\right)^{1-\alpha}
$$

The first order condition for (7) is then

$$
-\alpha \frac{F\left(V^{e}(z), z, z\right)-\kappa_{M}}{\partial F\left(V^{e}(z), z, z\right) / \partial V}=(1-\alpha)\left(V^{e}(z)-V^{u}(z)\right)
$$

\footnotetext{
${ }^{3}$ Rudanko (2005, Prop. 2.4) starts from a framework of competitive search and shows that the equilibrium is the same as with Nash bargaining where the bargaining weight of the worker equals the elasticity of matches w.r.t. unemployment. For our purposes, we can start right away with the Nash bargaining framework.
} 
Because of the envelope condition

$$
\frac{\partial F\left(V^{e}(z), z, z\right)}{\partial V}=-\frac{1}{u^{\prime}(w(z, z))}
$$

we can write (8) as

$$
\alpha\left(F^{e}(z)-\kappa_{M}\right) u^{\prime}\left(w^{e}(z)\right)=(1-\alpha)\left(V^{e}(z)-V^{u}(z)\right)
$$

which is analogous to (5).

\subsection{Labor Market Clearing}

To close the model, notice that the outside option of the worker satisfies

$$
V^{u}(z)=u(b)+\beta \mathrm{E}_{z}\left[V^{u}\left(z^{\prime}\right)+p^{W}\left(z^{\prime}\right)\left(V^{e}\left(z^{\prime}\right)-V^{u}\left(z^{\prime}\right)\right)\right]
$$

Vacancy creation by firms is governed by the zero-profit condition

$$
p^{F}(\theta(z))\left(F^{e}(z)-\kappa_{M}\right)=\kappa
$$

Equs. (11) and (12) are valid in all the contracting environments we consider.

\subsection{The persistence of vacancies}

If $\alpha_{z}>0$, the labor productivity of a match depends not only on the current state of aggregate productivity $(z)$, but also on the level of productivity when the match was formed $\left(z_{m}\right)$. Consider a match where $z_{m}>z$, which is more productive than a match created in the current period. Imagine that the worker and the firm separate because they fail to come to an agreement on the wage. This never happens in equilibrium, but out-of-equilibrium behavior is important for the negotation process. If the firm fills the job with a new worker, does the productivity advantage of the match persist or not? In the first case, we could say that embodied technology is job-specific, in the second case it is match-specific. So far we have assumed it is match-specific, what changes if we make it job-specific? In that case, the voluntary separation between firm and worker (out of equilibrium) can create a vacancy with positive value. This affects the Nash bargaining outcome, because the outside option of the firm is not zero any longer, but equals the value of the vacancy.

I have modified the model so as to account for this possitibility, and run some numerical experiments with the model of continuous re-bargaining. It turns out that job-specific technology has some effect on the dynamics of wages, but very little effect on the dynamics of unemployment, for the following reason. At the time when the firm and the worker first meet, the value of the vacancy is zero, because of (12), no matter whether the vacancy may become valuable later or not. Since the match never separates endogenously in equilibrium, the surplus at the time of the match formation, which is what determines hiring incentives, is not affected by whether the vacancy may be valuable later on. The question of job-specific technology may become more important if workers and firm can separate for reasons other than the destruction of the job (for example, because a worker moves to a different city). 


\section{The Effects of Embodied Technical Change}

Before presenting numerical results of the model, I want to analyze the effects of the technology specification (1) in the standard model of continuous Nash bargaining, for which approximate results can be derived analytically. To simplify the algebra, I write the model in continuous time, and I choose $A_{m}=1$ and $\alpha=0.5$ in the matching function (2) and in the bargaining function (10). There are only two aggregate productivity states $z_{c} \in\left\{z_{\text {good }}, z_{b a d}\right\}$. Productivity switches between the two states at the rate of probability $\sigma$. Then we get the set of Bellman equations

$$
\begin{aligned}
r V\left(z_{c}, z_{m}\right) & =w\left(z_{c}, z_{m}\right)+\delta\left(V^{u}\left(z_{c}\right)-V\left(z_{c}, z_{m}\right)\right)+\sigma\left(V\left(z_{\phi}, z_{m}\right)-V\left(z_{c}, z_{m}\right)\right) \\
r V^{u}\left(z_{c}\right) & =b+p^{W}\left(z_{c}\right)\left(V\left(z_{c}, z_{c}\right)-V^{u}\left(z_{c}\right)\right)+\sigma\left(V^{u}\left(z_{\phi}\right)-V^{u}\left(z_{c}\right)\right) \\
r F\left(z_{c}, z_{m}\right) & =Y\left(z_{c}, z_{m}\right)-w\left(z_{c}, z_{m}\right)+\delta\left(0-F\left(z_{c}, z_{m}\right)\right)+\sigma\left(F\left(z_{\phi}, z_{m}\right)-F\left(z_{c}, z_{m}\right)\right) \\
F\left(z_{c}, z_{m}\right) & =V\left(z_{c}, z_{m}\right)-V^{u}\left(z_{c}\right) \\
\kappa & =p^{F}\left(z_{c}\right) F\left(z_{c}, z_{c}\right)
\end{aligned}
$$

where $z_{\phi}$ denotes the state that is not $z_{c}$. Defining the worker's surplus as $S\left(z_{c}, z_{m}\right) \equiv$ $V\left(z_{c}, z_{m}\right)-V^{u}\left(z_{c}\right)$ and using $p^{W}\left(z_{c}\right)=1 / p^{F}\left(z_{c}\right)$, we can condense (13) to

$$
\begin{aligned}
(r+\delta+\sigma) S\left(z_{c}, z_{m}\right)+p^{W}\left(S\left(z_{c}, z_{c}\right)\right) S\left(z_{c}, z_{c}\right)-\sigma S\left(z_{\phi}, z_{m}\right) & =w\left(z_{c}, z_{m}\right)-b \\
(r+\delta+\sigma) S\left(z_{c}, z_{m}\right)-\sigma S\left(z_{\phi}, z_{m}\right) & =Y\left(z_{c}, z_{m}\right)-w\left(z_{c}, z_{m}\right)
\end{aligned}
$$

Adding (14a) and (14b) we obtain an equation defining the surplus:

$$
2(r+\delta+\sigma) S\left(z_{c}, z_{m}\right)+p^{W}\left(S\left(z_{c}, z_{c}\right)\right) S\left(z_{c}, z_{c}\right)-2 \sigma S\left(z_{\phi}, z_{m}\right)=Y\left(z_{c}, z_{m}\right)-b
$$

From (15) and (13d) we obtain

$$
\begin{aligned}
p^{W *} & =\kappa^{-1} S^{*}=\kappa^{-1} \frac{1-b}{2(r+\delta)+p^{W *}} \\
\frac{d p^{W}}{d z_{c}} & =\kappa^{-1}\left(S_{c}^{*}+S_{m}^{*}\right)
\end{aligned}
$$

where the asterisk denotes steady state values, and the subscripts 'c' and 'm' denote partial derivatives with respect to current and match-time productivity.

Next we derive a linear approximation of (15) at the steady state. Assume that $\left(z_{\text {good }}, z_{\text {bad }}\right)=1 \pm \Delta z$ such that $\frac{d z_{\phi}}{d z_{c}}=-1$. Differentiating (15) w.r.t. $z_{c}$ and $z_{m}$ at the steady state and using (16) gives

$$
\begin{aligned}
2(r+\delta+\sigma) S_{c}^{*}+2 p^{W}\left(S^{*}\right)\left(S_{c}^{*}+S_{m}^{*}\right)+2 \sigma S_{c}^{*} & =1-\alpha_{z} \\
2(r+\delta+\sigma) S_{m}^{*}-2 \sigma S_{m}^{*} & =\alpha_{z}
\end{aligned}
$$

Notice that the derivative of $p^{W}\left(S\left(z_{c}, z_{c}\right)\right) S\left(z_{c}, z_{c}\right)$ w.r.t. $S\left(z_{c}, z_{m}\right)$ equals $p^{W}\left(S^{*}\right)+\frac{d p^{W}}{d S} S^{*}=$ $2 p^{W}\left(S^{*}\right)$. A higher surplus has two benefits for the worker. First, if she gets the job, it 
has more value. Second, the probability of getting the job increases, because the firm surplus in equilibrium rises proportionally to the worker surplus, and therefore the number of vacancies and the job finding probability rise.

Adding (17) and (18) and using (16b) we get

$$
\left[(r+\delta+2 \sigma)+p^{W}\left(S^{*}\right)\right] \kappa \frac{d p^{W}}{d z_{c}}=\frac{1}{2}+2 \sigma S_{m}^{*}=\frac{(r+\delta)+2 \sigma \alpha_{z}}{2(r+\delta)}
$$

Using $p^{W *}=\delta\left(1-U^{*}\right) / U^{*}$ we can write this as

$$
\frac{d p^{W}}{d z_{c}}=\frac{1}{2(r+\delta) \kappa} \frac{r+\delta+2 \sigma \alpha_{z}}{r+\delta / U^{*}+2 \sigma}
$$

Inspecting (20), we learn two important things. First, the responsiveness of the job finding rate to changes in labor productivity, $\frac{d p^{W}}{d z_{c}}$, increases in $\alpha_{z}$. Second, this effect is stronger if $\sigma$ is higher (relative to $r$ and $\delta$ ): the faster the aggregate state changes, the more important it becomes for a firm in the good state to lock in the high productivity by creating new jobs. This comes from the term $2 \sigma S_{m}^{*}$ in (19). A higher $\sigma$ means a higher probability of switching to the bad state, which deteriorates the outside option of the worker. This increases the part of the productivity gain of $z_{m}$ that goes to the firm.

What does the model imply for wages? Subtracting (14b) from (14a) we obtain

$$
2 w\left(z_{c}, z_{m}\right)=Y\left(z_{c}, z_{m}\right)+b+p^{W}\left(S\left(z_{c}, z_{c}\right)\right) S\left(z_{c}, z_{c}\right)
$$

Taking derivatives we get

$$
\begin{aligned}
2 w_{c} & =1-\alpha_{z}+2 p^{W}\left(S^{*}\right)\left(S_{c}^{*}+S_{m}^{*}\right) \\
2 w_{m} & =\alpha_{z}
\end{aligned}
$$

For the entry wage $w^{e}$ we get

$$
\begin{aligned}
\frac{d w^{e}}{d z} & =w_{c}+w_{m}=\frac{1}{2}+p^{W *}\left(S_{c}^{*}+S_{m}^{*}\right) \\
& =\frac{1}{2}+S^{*} \frac{d p^{W}}{d z_{c}}=\frac{1}{2}+\frac{1-b}{2(r+\delta)+p^{W *}} \frac{d p^{W}}{d z_{c}}=\frac{1}{2}+\frac{p^{W *}(1-b)}{2(r+\delta)+p^{W *}} \eta_{z_{c}}^{p^{W}} \\
& \approx \frac{1}{2}+(1-b) \eta_{z_{c}}^{p^{W}}
\end{aligned}
$$

where we have defined the elasticity $\eta_{z_{c}}^{p^{W}} \equiv \frac{d p^{W}}{d z_{c}} \frac{z^{*}}{p^{W *}}=\frac{d p^{W}}{d z_{c}} \frac{1}{p^{W *}}$ and used again that $p^{W *}>>$ $r+\delta$. Equ. (24) shows that the variability of entry wages depends on the product of the instantaneous match surplus $(1-b)$ and the elasticity $\eta_{z_{c}}^{p^{W}}$. If $(1-b)$ is small, wages cannot fluctuate very strongly because they are tied to productivity. If $\eta_{z_{c}}^{p^{W}}$ is high, wages tend to fluctuate a lot, because the changes in job finding probability make the outside option of the worker fluctuate. Existing specifications of the matching model have moderate wage fluctuations because either $\eta_{z_{c}}^{p^{W}}$ is small (Shimer 2005) or $1-b$ is small (Hagedorn and Manovskii 2005) or the real wage is assumed to be rigid (Hall 2005). Our model allows both $\eta_{z_{c}}^{p^{W}}$ and $1-b$ to be big, and wage fluctuations can become very strong. 


\section{Data and calibration}

\subsection{The cyclicality of labor market aggregates}

Table 1, which is reproduced ${ }^{4}$ from Shimer (2005, Table 1), provides statistics about quarterly US labor market aggregates from 1951-2003. The key finding is the very high

Table 1: Summary Statistics, Quarterly U.S. Data, 1951-2003

\begin{tabular}{lrrrrrr} 
& & Unempl. & Vac. & $\theta$ & $p^{W}$ & $z$ \\
\hline StDev & 0.190 & 0.202 & 0.382 & 0.118 & 0.020 \\
Quart.Autocorr. & 0.936 & 0.940 & 0.941 & 0.908 & 0.878 \\
\hline \multirow{4}{*}{ Corr.Matrix } & $\mathrm{U}$ & 1 & 0.894 & 0.971 & 0.949 & 0.408 \\
& $\mathrm{~V}$ & & 1 & 0.975 & 0.897 & 0.364 \\
& $p^{W}$ & & & 1 & 0.948 & 0.396 \\
& $z$ & & & & 1 & 0.396 \\
& & & & & 1 \\
\hline
\end{tabular}

Source: Shimer (2005, Table 1)

variability of unemployment and vacancies relative to labor productivity. An important criterion to judge the model will be whether it is able to match those data.

\subsection{The cyclicality of real wages}

The relationship of wages and the business cycle has received a lot of attention in the literature. Empirical studies based on macroeconomic data usually find that wages are only mildly procyclical (Abraham and Haltiwanger 1995). For the time period 1951-2003, hourly compensation and hourly labor product in the nonfarm business sector (after taking logs and detrending) have a correlation coefficient of 0.508 . The regression coefficient of wages on productivity is $0.575 .{ }^{5}$ If we measure cyclicality by the correlation of wages and unemployment, we find that that hourly compensation in the nonfarm business sector has a correlation with the unemployment rate (detrended, but no logs) of -0.279 , and a regression coefficient of -0.204: a one percentage point increase in unemployment is related to a 0.204 percent reduction in wages. Based on this finding, some recent papers (Hall (2005), among others) have argued that the low responsiveness of real wages to aggregate productivity is a key element in explaining the high variability of unemployment.

Studies using panel data tend to find a stronger procyclicality of wages, partly because they can control for the composition bias in the workforce over the cycle (Solon, Barsky, and Parker 1994). This finding has been reinforced by recent studies which distinguish

\footnotetext{
${ }^{4}$ I omit the information on the separation rate, which is constant in my model.

${ }^{5}$ If we do the same exercise with productivity and compensation per worker, the corresponding numbers are 0.620 and 0.578 (Rudanko (2005, Section 3) reports similar numbers). To measure the cyclicality of wages, it makes more sense to use hourly compensation.
} 
the cyclicality of job stayers and job movers. Hart (2003) and Devereux and Hart (2005) for UK data, and many studies for US data (cf. Shin and Solon (2004) and references there) find that the wages of workers when they change jobs are significantly more flexible than the wages of those who stay in the same job (wages of workers who change the job but stay in the same firm are somewhere in-between). The results summarized in Table 2 find that a one percentage point increase in the unemployment rate is associated with a reduction in the real wage of male job stayers of 1-2 percent, and of male job movers of 2-3 percent. Notice that the micro-studies find a much stronger response even for job stayers than what we found above in the the macro data. The evidence that entry wages display

Table 2: Effect of unemployment on wages

\begin{tabular}{l|rrrr} 
& \multicolumn{2}{|c}{ Male } & \multicolumn{2}{c}{ Female } \\
& Stayers & Movers & Stayers & Movers \\
\hline Hart (2003, Table 3) & -1.22 & -2.01 & -1.30 & -1.70 \\
Devereux and Hart (2005, Table 3) & -1.73 & -2.92 & -1.66 & -2.49 \\
Shin and Solon (2004, Tables 1-4) & $\approx-1.00$ & & & \\
\hline
\end{tabular}

Notes: external movers in the case of Devereux and Hart (2005)

considerable cyclicality undermines the argument that real wage rigidity is the source of the large unemployment fluctuations, because it is the wages for new hires what determines the firms' incentives to create vacancies. It gives a reason to look for theories that can explain unemployment variability without resorting to wage rigidity, which is what this paper does. The findings also suggest some form of long-term wage contracting between the firm and the worker, where the firm insures the worker against wage fluctuations, as long as the worker stays within the firm.

That the labor market is not a spot market where wages are renegotiated from scratch every period is also found in a related strand of literature which identifies cohort effects in wages. The time at which a worker enters a firm or enters the labor market for the first time, has a persistent effect on a wage. Workers who entered in a recession will receive lower wages than workers who entered in a boom. This effect remains even many years after entering the firm (see for example Beaudry and DiNardo (1991), Baker, Gibbs, and Holmstrom (1994), Oreopoulos, von Wachter, and Heisz (2006)). We will discuss the findings of the latter study in more detail in Section 5.3, where we compare it to the implications of our model. This difference in the dynamics of entry wages and wages of ongoing matches is what one would expect from the theory of implicit contracts: while they are on the same job (or at least within the same firm), workers are partially insured by their firms against wage fluctuations. New entrants, in contrast, get a higher wage in a boom, which reflects the higher discounted lifetime productivity of the match. These findings are interesting because the technology specification (1) potentially provides an alternative explanation. Unemployment at the time of entry into a job may seem to cause persistently lower wages because the jobs that are created in bad times are less productive. 
We will see whether we can distinguish this explanation from an explanation based on long-term wage contracting.

The relationship between wages and the unemployment rate, which is the focus of the empirical labor literature, is hard to interpret, because unemployment is endogenous. Thinking in terms of the Mortensen/Pissarides model, it makes more sense to estimate the responsiveness of wages to changes in labor productivity, not unemployment. In yet preliminary work based on CPS data, Haefke, Sonntag, and van Rens (2006) report the elasticity of wages with respect to aggregate labor productivity. For job movers, they find an elasticity of about 1, while for job stayers, they find an elasticity of about 0 . This supports the idea that entry wages, which determine the hiring incentives of firms, are flexible, while the wages of incumbents are very rigid. How this can be reconciled with the seemingly strong reaction of the wages of job stayers to unemployment is not yet clear. Both labor productivity and unemployment act on wages, one through the current match surplus, the other one through the continuation value of the match. The two are strongly correlated. Future empirical work should try to disentangle the two effects.

\subsection{Parameter values}

The model period is 1/48 of a year, corresponding roughly to a week. For the parameters I use standard values from the literature. The discount rate is set to $1.2 \%$ quarterly, so $\beta=0.988^{1 / 14}$. I use $\log$ utility, $U(c)=\log x$. The parameter $b$, which captures both unemployment benefits and the value of leisure, is the key parameter that determines the volatility of tightness and unemployment. I use 0.745 from Costain and Reiter (2003, Table 1), which gives a realistic response of the model to long-run changes in unemployment benefits and taxation. ${ }^{6}$

For the elasticity of matches w.r.t. unemployment I use $\alpha=0.4$. This is well within the range of values that Petrongolo and Pissarides (2001, Table 3) report. With this value, the model strikes a balance between explaining the variability of unemployment and the variability of tightness. If I use a higher value of $\alpha$ as Shimer (2005) and Rudanko (2005) do, the model tends to underestimate the variability of unemployment, and overestimate that of tightness. In this sense, the parameter is "estimated" from the data. For the job separation rate, some recent papers have used a value of $40 \%$ annually. Here I deviate and rather use $25 \%$ annually, $\delta=0.25 / 48$, which is closer to what earlier papers in the matching literature have used. The main reason is that I assume in the model that technical progress is linked to the match, not to the job, while in reality it is probably a mixture of both. Using a separation rate of 0.4 dilutes the effect of embodied technical change too much. The matching efficiency $A_{m}$ is normalized to unity; this parameter only scales the absolute number of vacancies, which is irrelevant for us. In each experiment, the vacancy cost parameter is set such that the steady state unemployment rate is 5.67 percent, the average in the US in the period 1951-2003.

\footnotetext{
${ }^{6}$ In the 2003 version of the paper, we considered this more of an upper bound for the parameter. Our more recent, not yet published empirical results indicate that this parameter is our best point estimate.
} 
For the productivity process, I use a 9-state Markov chain. From each state, only neighbouring states can be reached within one model period. The transition probabilities where chosen such that in each state, the conditional expectation satisfies $\mathrm{E}_{t} z_{t+1}=\rho_{z} z_{t}$, and the conditional standard deviation is $\sigma_{z}$. I choose $\rho_{z}$ so as to match approximately the quarterly autocorrelation coefficient of average labor productivity (which is not equal to $z$ in the case $\alpha_{z}>0$ ) of 0.878 . Average labor productivity varies somewhat with $\alpha_{z}$, but I keep the $\rho_{z}$ constant at $\rho_{z}=0.87^{1 / 12}$ in all simulations. The states where chosen such that the outer points are \pm 2.5 times the unconditional standard deviation of $z$. The variance $\sigma_{z}$ is varied systematically to study the nonlinear effects of fluctuations.

The sunk cost $\kappa_{M}$ of match formation is set to 0 unless stated otherwise. If current productivity is $z$, to keep a match that was formed while productivity was $z_{m}$ we need a sunk cost of approximately $\kappa_{M}=\max \left\{0, \frac{\alpha_{z}\left(z-z_{m}\right)}{1-\beta(1-\delta)}-\left(S^{*}+F^{*}\right)\right\}$. In the cases where the sunk cost is used to prevent all endogenous separations, I therefore set $\kappa_{M}=$ $\max \left\{0, \frac{\alpha_{z} \Delta z}{1-\beta(1-\delta)}-0.75\left(S^{*}+F^{*}\right)\right\}$, where $\Delta z$ is the difference between the highest and the lowest possible realization of $z$.

\section{$5 \quad$ Numerical Results}

\subsection{Explaining Labor Market Aggregates: The Case Of Small Shocks}

We first investigate the case where the shocks to aggregate productivity $z$ are small. In this way, we abstract from two issues. First, the participation constraints in (6) never bind, such that the limited-commitment solution equals the full commitment solution, and wages are constant over the lifetime of a match. Second, there are no endogenous separations. Figure 1 displays results for this case, varying the parameter $\alpha_{z}$ between 0 and 1 . The panels on the lhs of the figure show the standard deviation of the variables, relative to the standard deviation of aggregate labor productivity (average productivity over the crosssection of matches). The rhs panels show the regression coefficient of the same variables on aggregate productivity, which equals the relative standard deviation of the two series multiplied with the correlation coefficient. We compare three different environments. First, the model with benchmark parameters and full commitment ("FullC"). Second, the model with short term wage contracts (continuous re-bargaining, "re-bargain"). For this model, I use linear utility rather than log-utility. The reason is that the Nash formula (10), which weighs the worker's surplus by the marginal utility at current wages, implies what I consider artificial fluctuations in the surplus sharing if utility is nonlinear and if the wage fluctuates as strongly as it does in the model with short term contracts. ${ }^{7}$ The third version is again with short term contracts, but assuming a very high sunk cost $\kappa_{M}$ of match formation, $\kappa_{M}=24$, equal to half a year of average labor productivity ("re-b,SunkC"). The purpose

\footnotetext{
${ }^{7}$ In that case, unemployment fluctuations would be about 10 percent higher than what they are in the graph.
} 
here is to study whether sunk costs have important effects on the dynamics of the model.

Four results stand out. First, the bargaining framework has almost no effect on unemployment and tightness, it only affects the dynamics of wages. This is in line with the results in Rudanko (2005). Second, the variability of average wages tends to be too big in the model with continuous re-bargaining, and too small in the model with wage contracts. Again, this is similar to what Rudanko finds. Third, the sunk cost has only a small effect on wage dynamics, and virtually no effect on unemployment and tightness. Fourth, and most importantly, the model can replicate the high volatility of unemployment and tightness if we pick the right $\alpha_{z}$. What the right $\alpha_{z}$ is depends on which aspects of the data we want to match. Shimer (2005) implicitly requires the model to replicate the volatility of labor market data (left panels), while Mortensen and Nagypal (2005, p.8) and Rudanko (2005, p.21) suggest that the model should only explain the part of the volatility in the data that is related to the movements of aggregate labor productivity (right panels). To match the first target, we need $\alpha_{z} \approx 0.65$, for the second target we need $\alpha_{z} \approx 0.28$.

\subsection{Big Shocks and Endogenous Separations}

Figure 2 shows results for the case $\alpha_{z}=0.28$, computed for different variances of the aggregate shock $z$. This illustrates the nonlinear effects that the variance of shocks has on the dynamics of the model. On the $\mathrm{x}$-axis we now have the standard deviation of average labor productivity (in the following denoted by $\sigma_{\text {ave } Z}$ ), which equals 0.02 in the data (Table 1). Notice that average labor productivity differs from $z$ in the case of $\alpha_{z}>0$, such that $\sigma_{\text {ave } Z}$ is an equilibrium outcome. We compare three different contracting frameworks. The model with continuous re-bargaining allows for endogenous separations. It turns out that they are very rare here, so that we do not see their effects in the figure. The solutions with full commitment ("FullC,SunkC") and with 1-sided commitment ("1LimC,SunkC") include a small sunk cost that prevents all endogenous separations. The sunk cost is set as explained in Section 4.3, and is maximally 2.3 weeks of production.

By our choice of $\alpha_{z}$, the variability of unemployment and tightness is much lower than in the data (lhs panels), but the elasticity w.r.t. $z$ is approximately right (rhs panels). We see that the nonlinear effect of $\sigma_{a v e Z}$ on the dynamics of unemployment and vacancies is small. A higher variance of shocks increases the relative variance of wages, because the participation constraint now starts to bind in some states, and firms have to adjust wages to prevent workers from quitting. However, this effect is not very big at the levels of $\sigma_{\text {ave } Z}$ that we consider. The variability of average wages under one-sided limited commitment solution is twice of what it is under full commitment, but it still falls short of the variability (elasticity w.r.t. productivity) that we observe in the data. I report results here for the case of one-sided commitment, because it is much faster to solve than the model with limited commitment on both sides, and the results are very similar. For example, in the case of Figure 2, with the highest $\sigma_{\text {ave }}$, the relative standard deviation of average wages is 0.3677 for one-sided commitment, and 0.3693 with limited commitment. The differences in the dynamics of unemployment and vacancies are even smaller.

Figure 3 shows the same information for the case $\alpha_{z}=0.65$. Endogenous separation 
is now a serious problem for the re-bargaining model. When it kicks in, the variability of unemployment goes up sharply (left panel). However, from the right panel we see that the negative correlation of unemployment with labor productivity disappears. This is because in times of high productivity, there is massive endogenous separation, leading to temporary spikes in unemployment. This is counterfactual. The full commitment and one-sided commitment solutions in the figure escape this problem by imposing sufficiently high sunk costs. ${ }^{8}$ If one accepts these costs (which are up to half a year of production!), the model is successful in matching the very high fluctuation of unemployment and vacancies. Even the variability of average wages is similar to what we find in the data, due to the high variability of entry wages.

To summarize, the model has no problem in explaining the systematic part (elasticity w.r.t. z) of unemployment and vacancies. The parameter values to achieve this cause only small levels of endogenous separations. A higher value of $\alpha_{z}$ can be used to generate unconditional variances of unemployment and vacancies as high as in the data, but drastic measures must be taken to prevent massive endogenous separations with counterfactual implications for the correlation of unemployment and labor productivity.

\subsection{The Dynamics Of Wages}

The conclusion from Figures 1 and 2 was that the variability of average wages tends to be too big in the model with continuous re-bargaining, and too small in the model with wage contracts. Figure 4 breaks this down into the movements of entry wages, wages of job stayers and average wages. The lhs panels show the elasticity of wages w.r.t. labor productivity, which is the natural thing to look at from an RBC perspective. The rhs panels show the elasticity of wages w.r.t. unemployment, which is what the bulk of the labor literature has focussed on. In Figure 4 we use $\alpha_{z}=0.28$, which appears to be the most plausible parameter value from the results above.

We confirm again that continuous re-bargaining generates wages that are too volatile, no matter whether we look at job stayers or movers. Let us therefore focus on long-term contracts. Then the elasticities w.r.t. labor productivity are in line with what Haefke, Sonntag, and van Rens (2006) report: about zero elasticity for job stayers, unit elasticity for new jobs. However, this conflicts with the evidence on average wages coming from aggregate data, where we found an elasticity of 0.575 , much higher than predicted by the model.

Concerning the relationship of wages and unemployment, the model predicts a regression coefficient between -2 and -3 for job movers ("entry wage"), which fits nicely with the microeconometric evidence reported in Table 2. The regression coefficient for job stayers, however, was about -1 in the data and is close to 0 in the model. Again there is a discrepancy between micro- and macro data, but this time in the other direction. In the macro

\footnotetext{
${ }^{8}$ Notice that the issue of sunk costs vs. endogenous separation has nothing to do with the type of wage bargaining. I demonstrate the effects of endogenous separation in the case of continuous re-bargaining rather than in the case of long-term contracts, because it is easier to solve.
} 
data, the regression coefficient of average wages on unemployment was only -0.204 , which is in line with the predictions of the model.

All in all, the success of the model in explaining wages is not completely clear. Let us therefore bring in some further piece of evidence, what the labor literature calls "cohort effects" on wages. I focus on the recent results in Oreopoulos, von Wachter, and Heisz (2006), who use a very comprehensive data set on Canadian college graduates in the 1980s and 1990s. They show that the cyclical conditions at the time a worker enters the labor market (graduates from college) has a persistent effect on wages. This effect is measured by a regression of log wages on the unemployment rate at the time of graduation. The regression controls for the unemployment rate of all years between graduation and the present day.

To compare these results with the model, I generate a panel of worker lifes from the model simulations. When the worker gets her first job, I interpret this as "entering the labor market". Then I follow this worker over the next 10 years, and see how the wage she gets (either in the initial job, or another job after an unemployment spell) depends on the initial unemployment rate. More precisely, I estimate the following regression, separately for each $E=0, \ldots, 10$ :

$$
\log w_{i, t+E}=\beta_{c}+\sum_{j=0}^{E} \beta_{e, j} U_{t+j}+\epsilon_{i, t+E}
$$

Here, $t$ is the time when worker $i$ enters the labor market, $E$ ("experience") denotes the time passed since entering the market, $w_{i, t+E}$ denotes the wage of the worker (wage of that week, conditional on the worker being employed), and $U_{t+E}$ is the unemployment rate (the average unemployment rate over the relevant year). Figure 5 reports the parameter estimate $\beta_{e, 0}$, which measures the effect of the initial unemployment rate, controlling for the history of aggregate unemployment over the working experience of the worker. The line "data" refers to the results in Oreopoulos, von Wachter, and Heisz (2006, Table 1,Col. 1). In the upper panel we see that a model with continuous Nash bargaining fails completely to explain the observed pattern. At labor market entry, the model grossly overestimates the effect of the unemployment rate, which is in line with our earlier findings. The next year already, the effect of the initial unemployment rate disappears, since the wage is re-bargained, and the current unemployment rate is controlled for in the regression. In contrast, the model with long-term contracts fits the data surprisingly well. The reduction in the impact of initial unemployment has a simple explanation in the model: a fraction of worker loose their job and find a new one, and in the new job the wage is negotiated afresh. In the data there may be some persistency of the wage even for job movers, but Oreopoulos, von Wachter, and Heisz (2006, p.26) find that changing employers is an important reason why workers starting in bad cyclical conditions catch up over time. The results for $\alpha_{z}=0$ are very similar to those of $\alpha_{z}=0.28$. With $\alpha_{z}=0.28$, the variance of both wages and unemployment is more than twice as large as with $\alpha_{z}=0$, but the regression coefficient does not change substantially. The fading effect of unemployment on wages comes from job separation, in both cases. 
Let us summarize the findings. More than the standard model, the model with embodied technical change $\alpha_{z}>0$ implies excessive volatility of real wages. To solve this problem, we have to introduce long-term wage contracts. Under this specification, the model fits well a number of stylized facts: that entry wages are more volatile than average wages, the elasticity of wages w.r.t. labor productivity, the relationship between unemployment and entry wages as well as the cohort effects that were found in the labor literature. What the model has difficulties to cope with is the cyclicality of the wages of job stayers, which seems stronger in the data than in the model. Shin and Solon (2004) find that much of this variability has to do with overtime pay and bonuses. It is plausible that firms, while insuring their workers against exogenous fluctuations, still use changes in wages to provide extra incentives. Then we need a more sophisticated model of long-term wage contracts.

\section{Conclusions}

The results in this paper have shown that the technological specification (1) helps to bring the standard labor market matching model in line with the data. Without resorting to any exogenous rigidities, the model explains the high variability of vacancies, job finding probabilities and the unemployment rate. The version with long-term wage contracting explains the the low volatility of the average wage, and the fact that wages of newly formed matches fluctuate more than average wages.

I conclude that Hypothesis 1 deserves closer investigation. Future work should improve on the present, very simple model in a number of ways. First, a better model would take endogenous separation seriously. The evidence from Bowlus (1995) indicates that people do quit jobs that were formed in recessions more frequently. This effect must be dampened, however, to avoid unrealistic spikes in unemployment. More generally, one should allow for heterogenous job separation probabilities. Some jobs were never meant to last long, while others are intended to be permanent jobs. Since the persistency of jobs relative to the persistency of aggregate productivity is crucial in generating unemployment volatility, it may be important to model this more carefully. A likely implication of the theory would be that the probability to find the kind of jobs that are long-lived fluctuates more strongly than the probability for short-term jobs. It may also be worthwhile to distinguish between job quality and match quality, allowing for a match to separate and the firm hanging on to a valuable vacancy. If this happens in equilibrium, it complicates the model significantly, since one has to keep track of the cross-sectional distribution of valuable vacancies in the economy. 


\section{References}

Abraham, K. G. and J. C. Haltiwanger (1995). Real wages and the business cycle. Journal of Economic Literature 33(3), 1215-1264.

Baker, G. P., M. Gibbs, and B. Holmstrom (1994). The wage policy of a firm. Quarterly Journal of Economics 109(4), 921-55.

Beaudry, P. and J. DiNardo (1991). The effect of implicit contracts on the movement of wages over the business cycle: Evidence from micro data. Journal of Political Economy 99, 665-688.

Beaudry, P. and C. Pages (2001). The cost of business cycles and the stabilization value of unemployment insurance. European Economic Review 45 (8), 1545-1572.

Bowlus, A. J. (1995). Matching workers and jobs: Cyclical fluctuations in match quality. Journal of Labor Economics 13(2), 335-50.

Costain, J. and M. Reiter (2003). Business cycles, unemployment insurance, and the calibration of matching models. CESifo Working paper 1008.

Devereux, P. J. and R. A. Hart (2005). Real wage cyclicality of job stayers, withincompany job movers, and between-company job movers. IZA DP 1651.

Fisher, J. D. M. (2006). The dynamic effects of neutral and investment-specific technology shocks. Journal of Political Economy 114, 413-51.

Haefke, C., M. Sonntag, and T. van Rens (2006). Wage rigidity and job creation. Presentation at SED meetings.

Hagedorn, M. and I. Manovskii (2005). The cyclical behavior of equilibrium unemployment and vacancies revisited. Manuscript.

Hall, R. E. (2005). Employment fluctuations with equilibrium wage stickiness. American Economic Review 95, 50-65.

Hart, R. A. (2003). Worker-job matches, job mobility, and real wage cyclicality. IZA DP 881.

Hornstein, A., P. Krusell, and G. L. Violante (2006). Vintage capital in frictional labor markets. Manuscript.

Miranda, M. J. and P. L. Fackler (2002). Applied Computational Economic and Finance. MIT Press.

Mortensen, D. T. and E. Nagypal (2005). More on unemployment and vacancy fluctuations. IZA DP 1765.

Oreopoulos, P., T. von Wachter, and A. Heisz (2006). The short-and long-term career effects of graduating in a recession: Hysteresis and heterogeneity in the market for college graduates. NBER Working Paper 12159.

Petrongolo, B. and C. Pissarides (2001). Looking into the black box: A survey of the matching function. Journal of Economic Literature 39(2), 390-431. 
Rudanko, L. (2005). Labor market dynamics under long term wage contracting and incomplete markets. Manuscript, University of Chicago.

Shimer, R. (2005). The cyclical behavior of equilibrium unemployment and vacancies. American Economic Review 95, 25-49.

Shin, D. and G. Solon (2004). New evidence on real wage cyclicality within employeremployee matches. Manuscript.

Solon, G., R. Barsky, and J. A. Parker (1994). Measuring the cyclicality of real wages: How important is composition bias? Quarterly Journal of Economics 109(1), 1-26. 
Unempl.
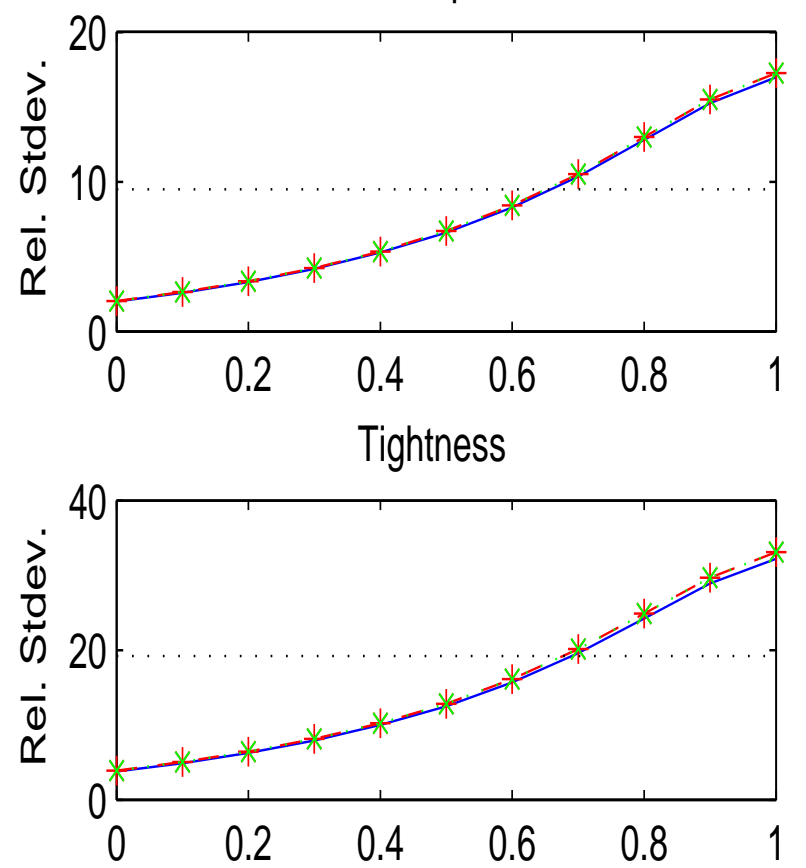

Ave. wage

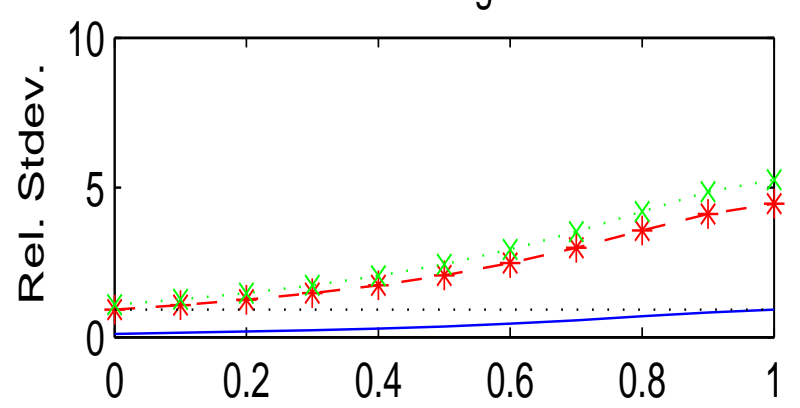

Entry wage

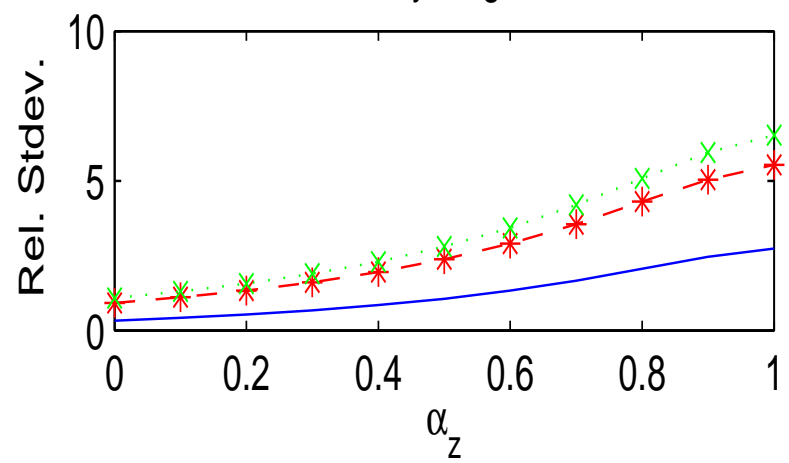

Unempl.

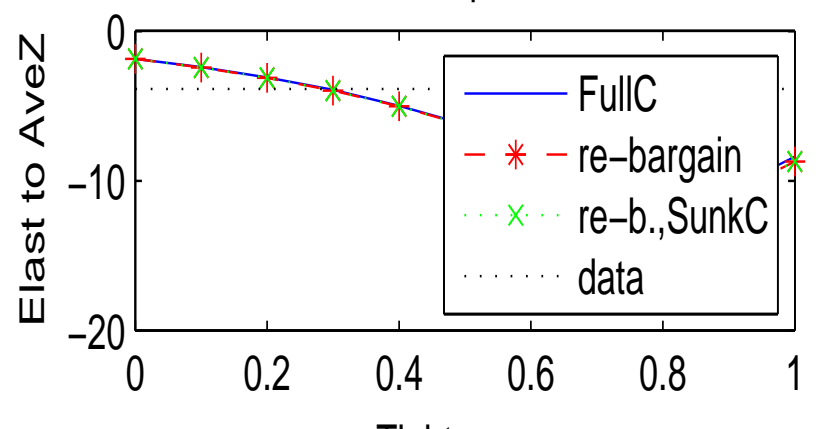

Tightness

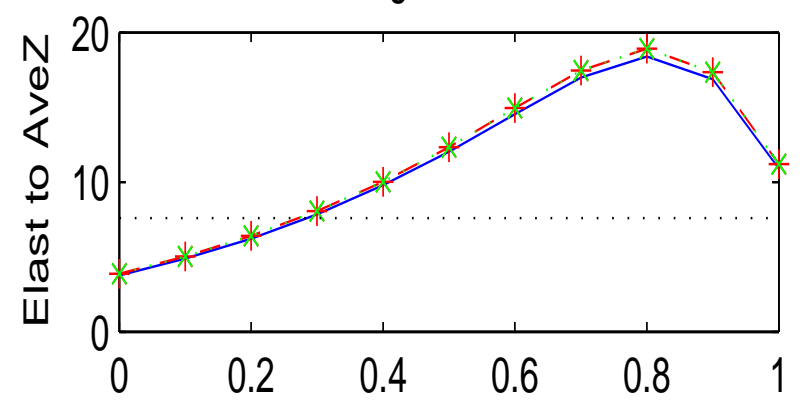

Ave. wage

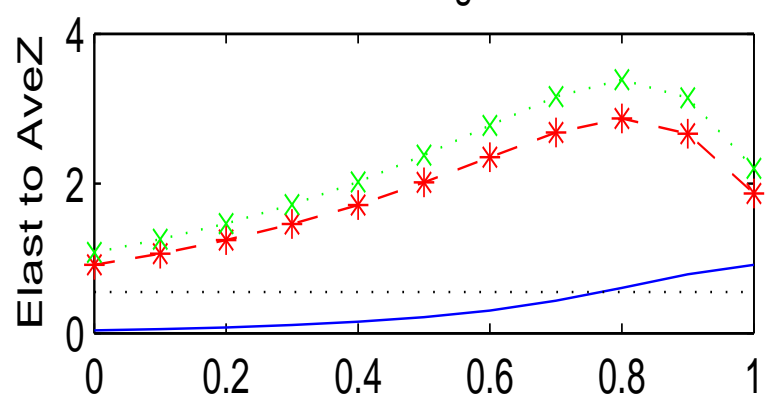

Entry wage

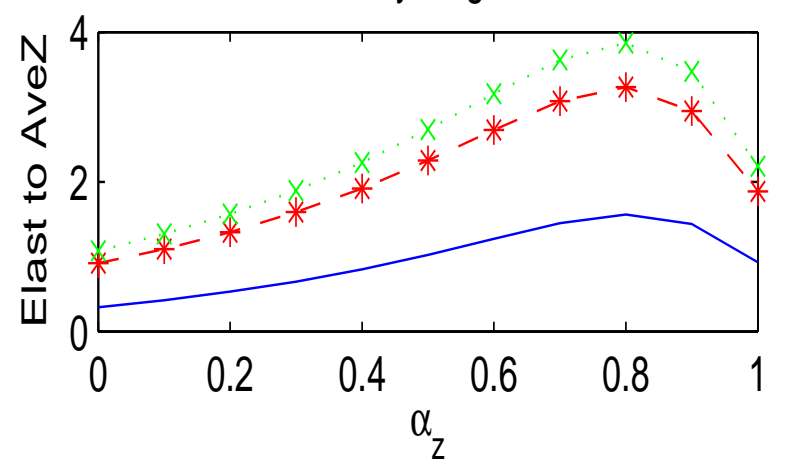

Figure 1: Model results for small shocks; mean of 100 simulations over 53 years, HP-filtered with $\lambda=10^{5}$ 
Unempl.
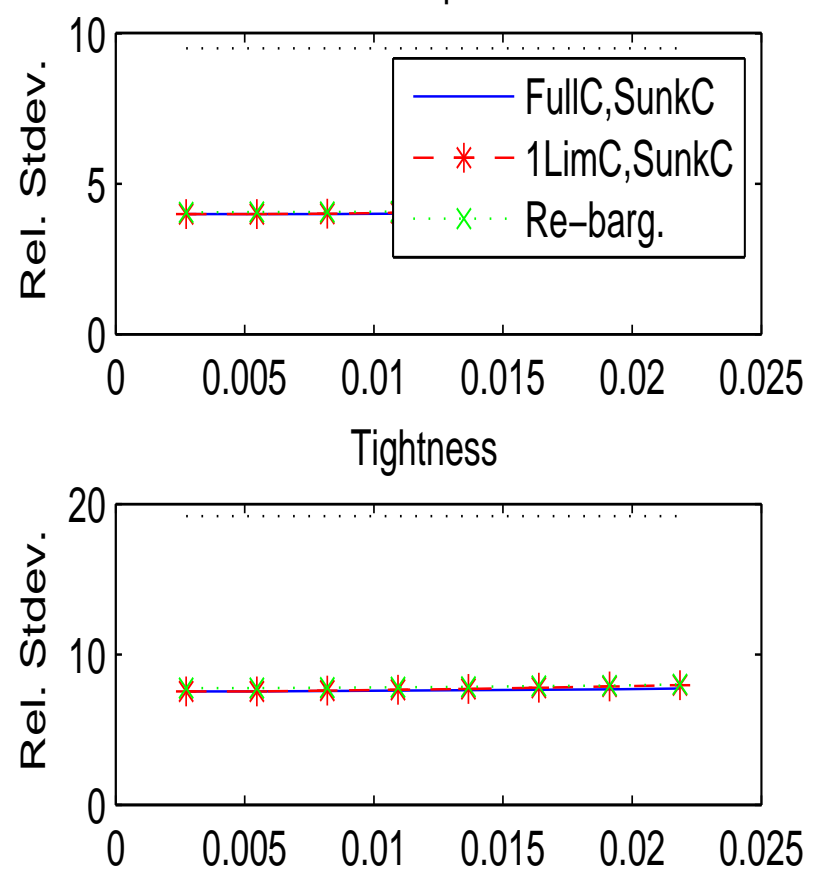

Ave. wage

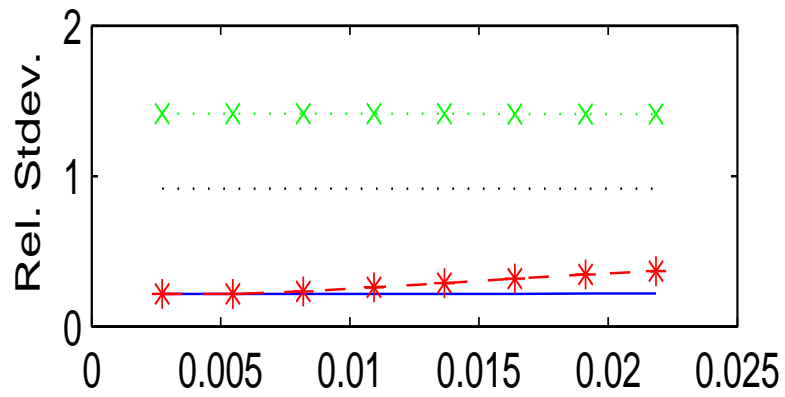

Entry wage

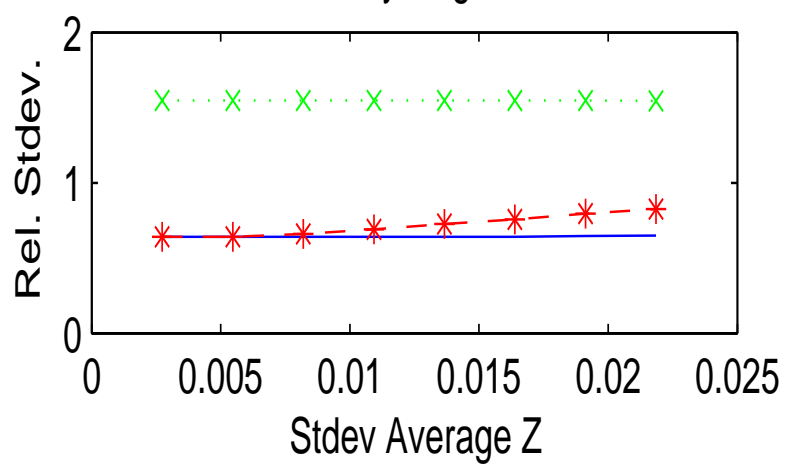

Unempl.

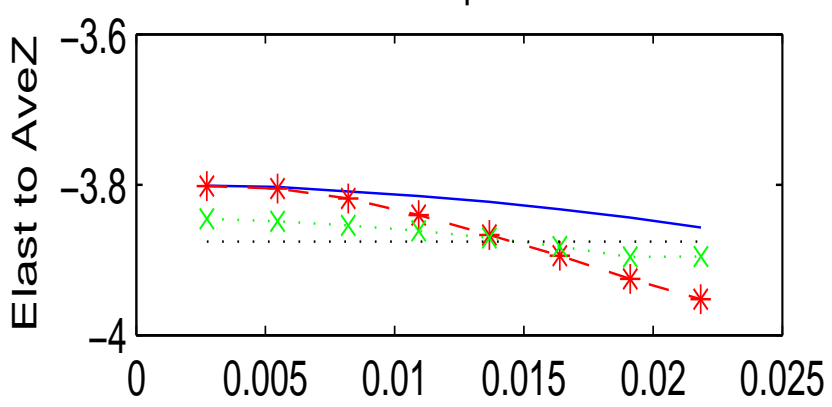

Tightness

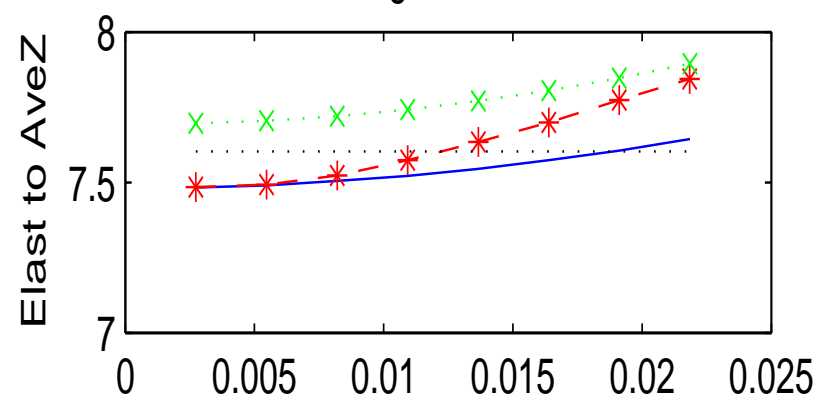

Ave. wage

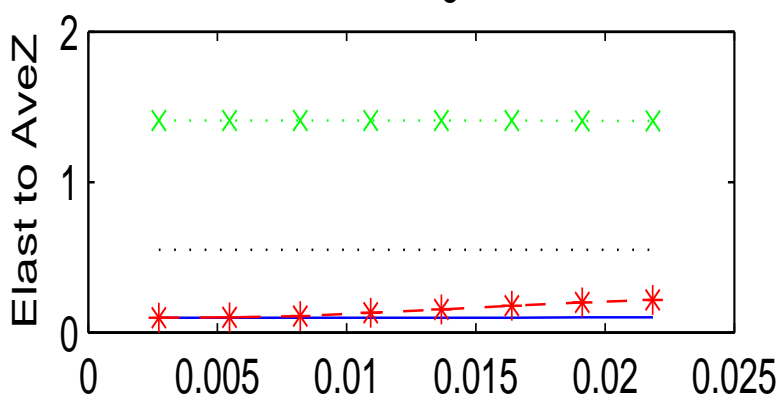

Entry wage

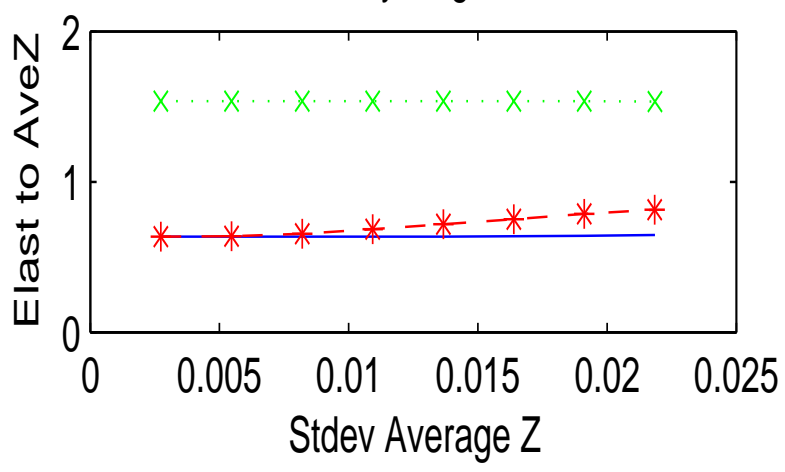

Figure 2: Model results with $\alpha_{z}=0.28$; mean of 100 simulations over 53 years, HP-filtered with $\lambda=10^{5}$ 
Unempl.
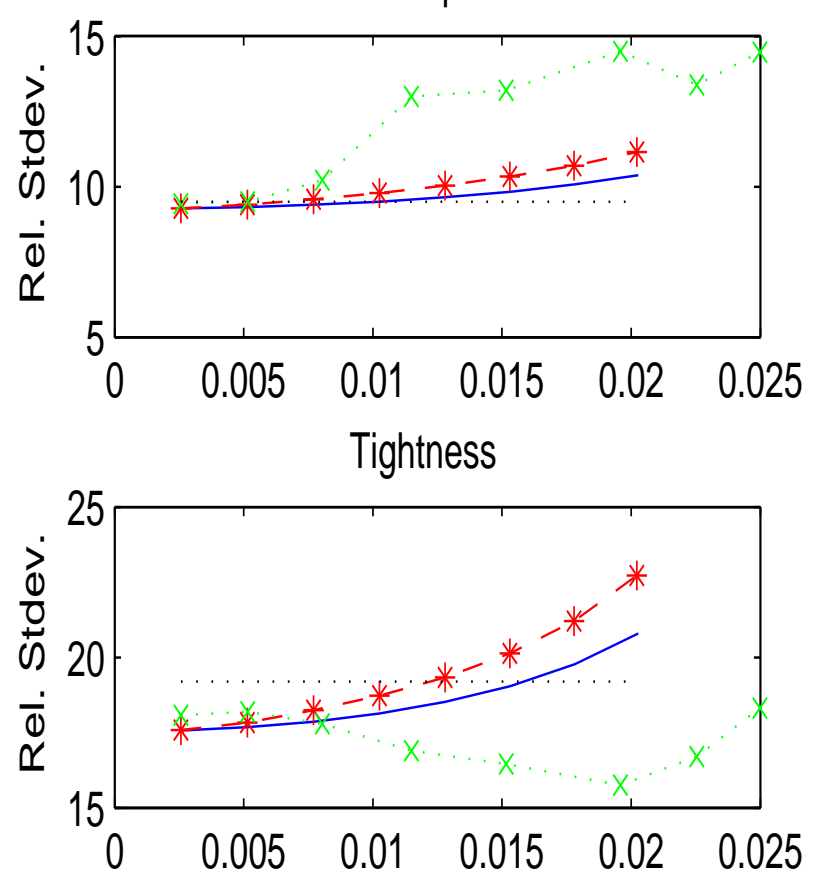

Ave. wage

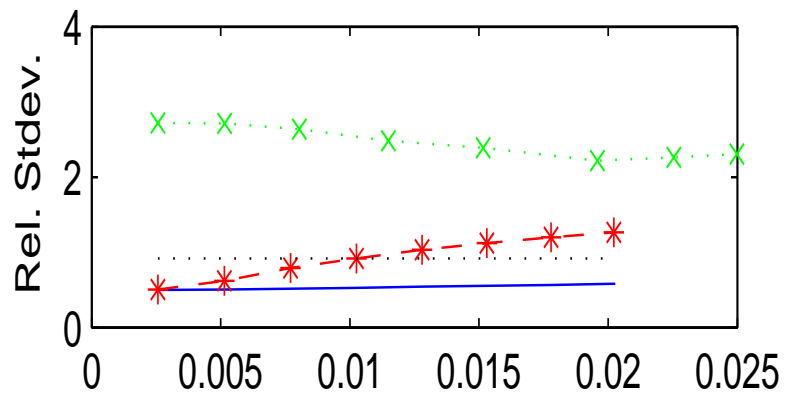

Entry wage

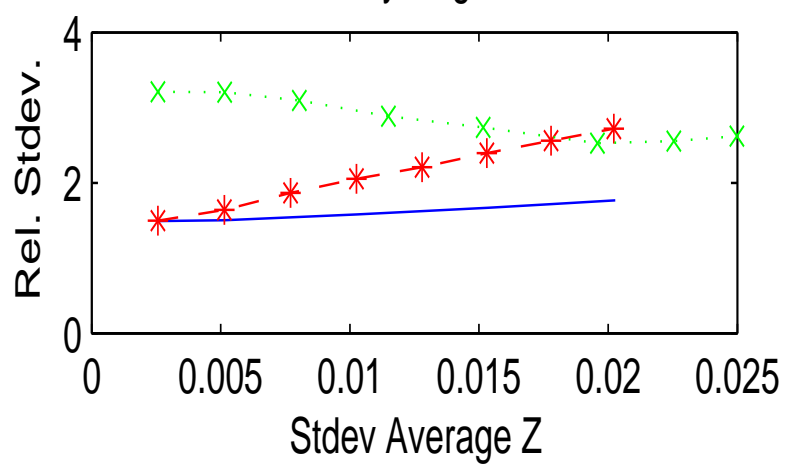

Unempl.

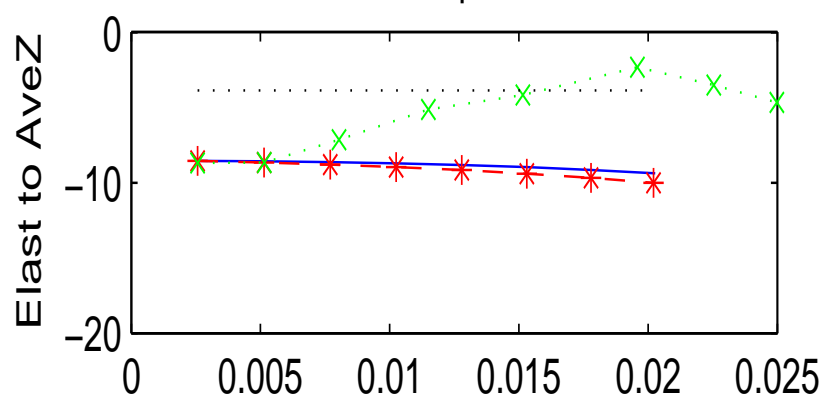

Tightness

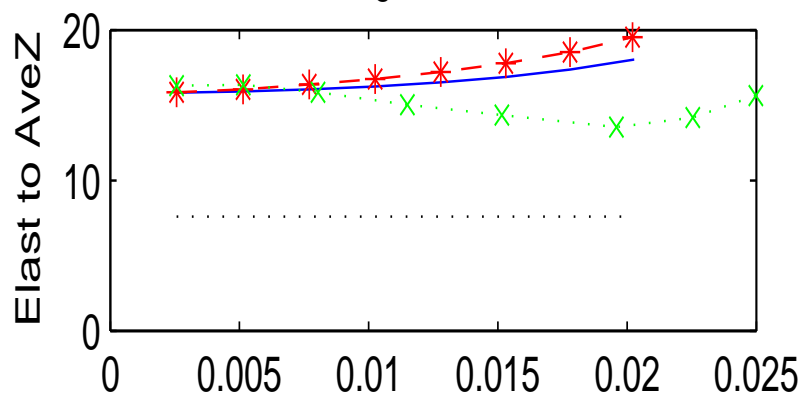

Ave. wage

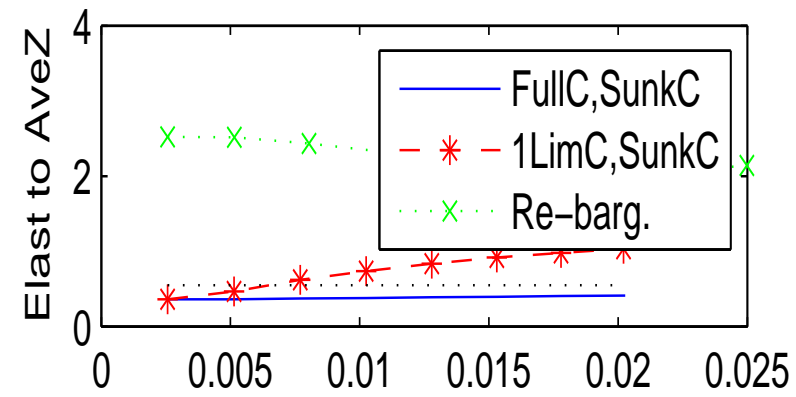

Entry wage

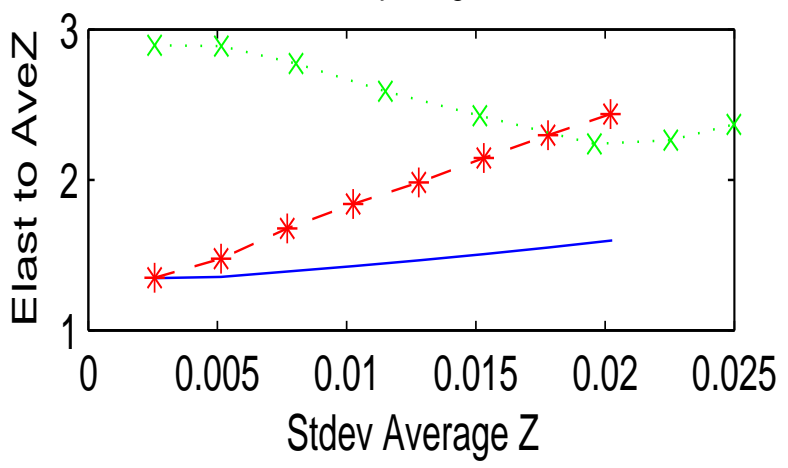

Figure 3: Model results with $\alpha_{z}=0.65$; mean of 100 simulations over 53 years, HP-filtered with $\lambda=10^{5}$ 

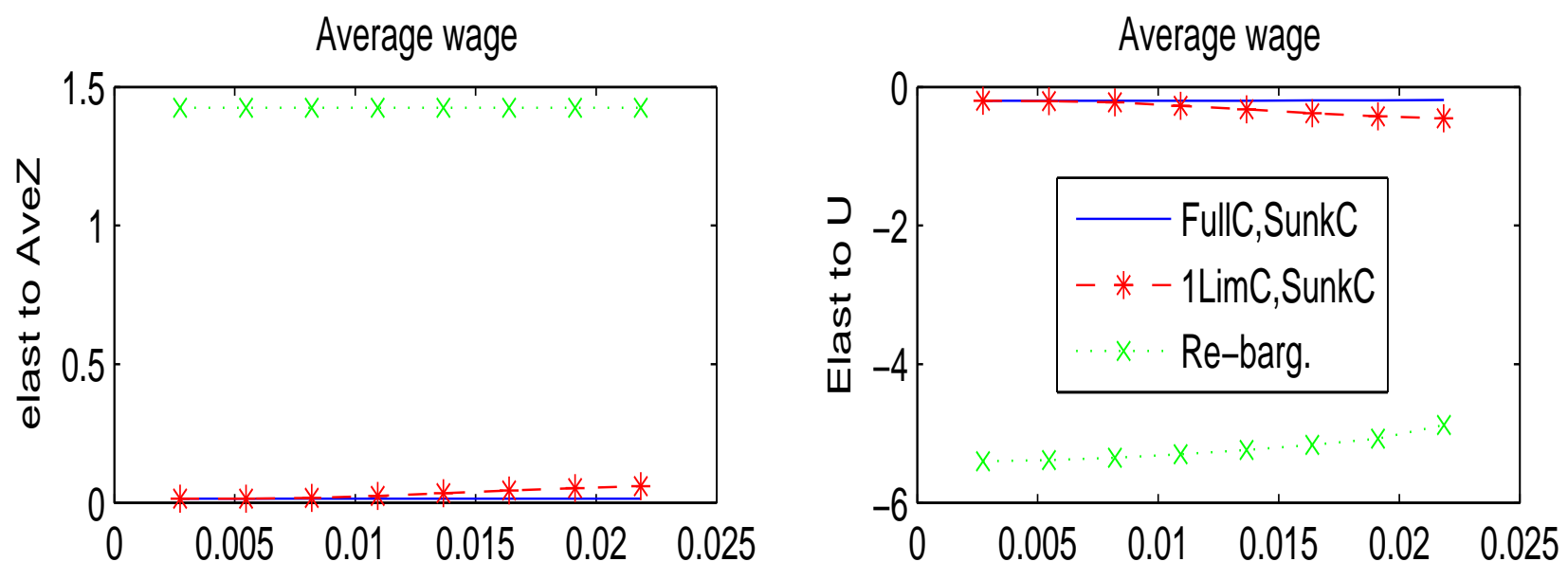

Entry wage

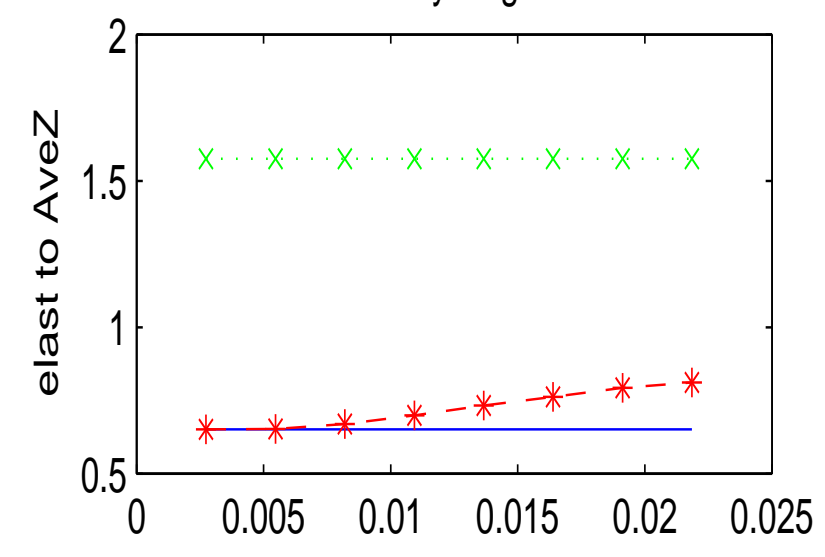

Entry wage
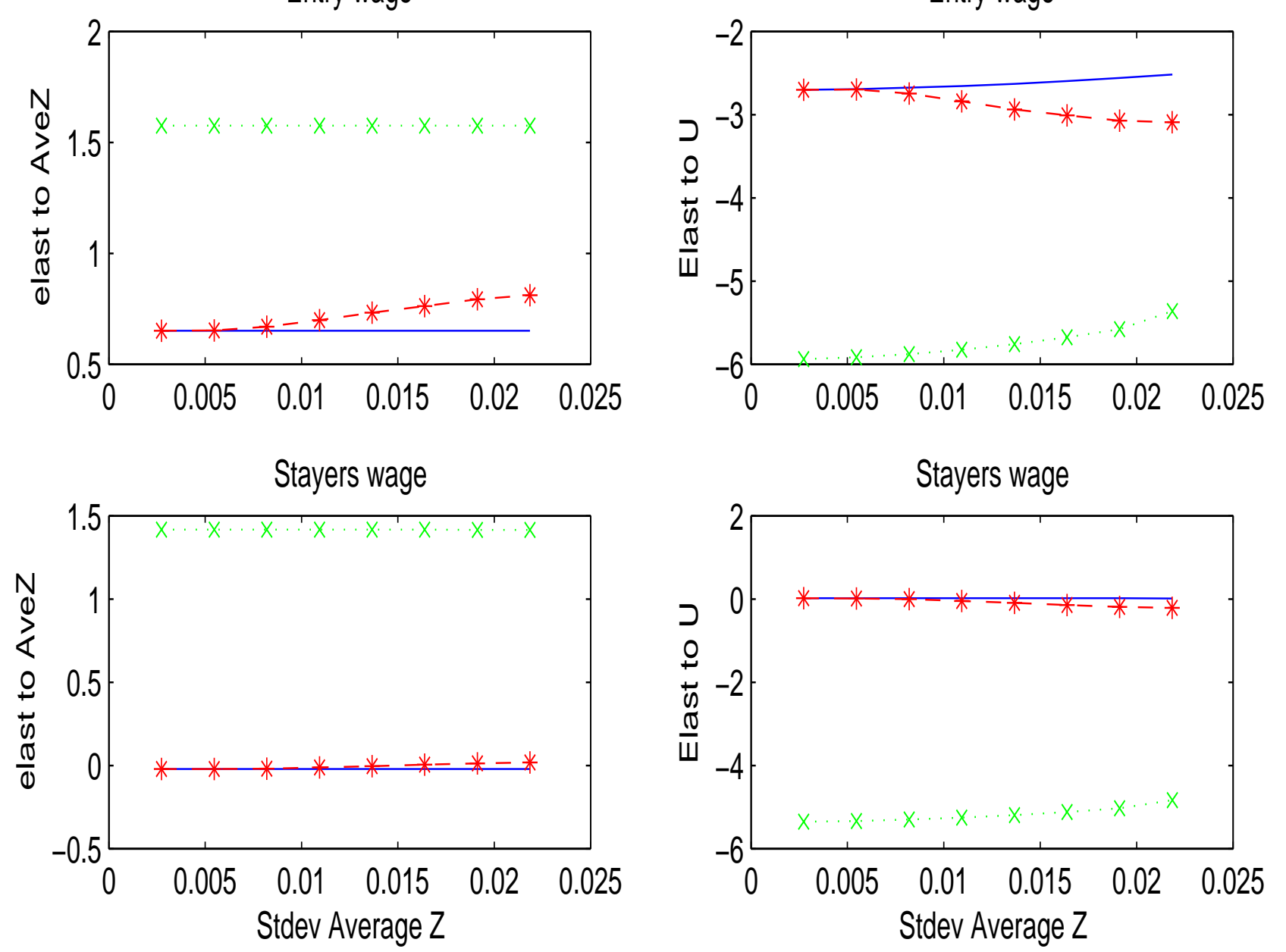

Figure 4: Model results with $\alpha_{z}=0.28$; mean of 100 simulations over 53 years, HP-filtered with $\lambda=10^{5}$ 

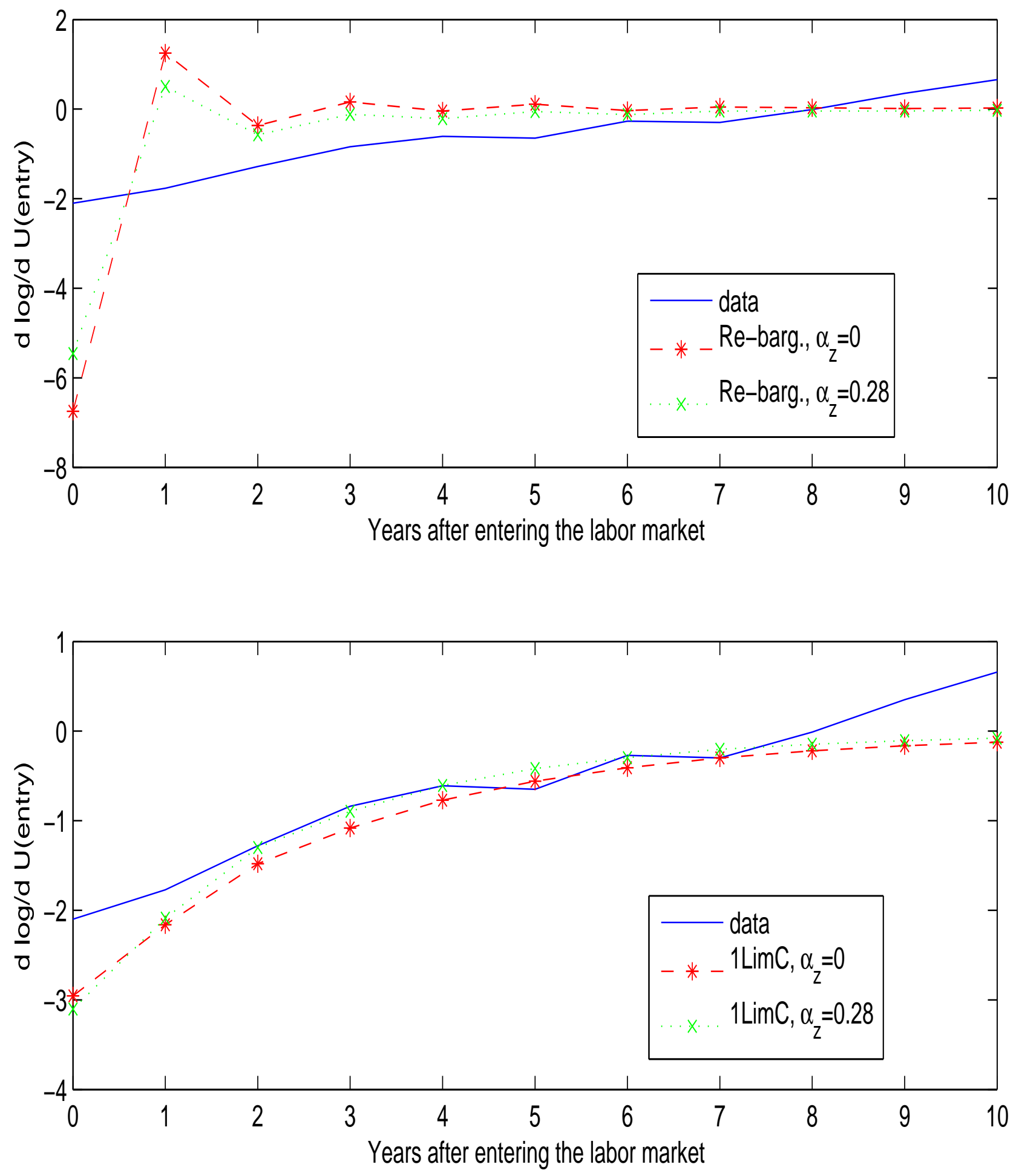

Figure 5: Influence of unemployment rate at time of labor market entry on wages, $\alpha_{z}=0.28$ 